\title{
Motives and Level of Physical Activity among School Teachers
}

\author{
Azlan Ahmad Kamall ${ }^{1 *}$, Mohd Radzani², and Arziani Jannah ${ }^{1}$ \\ ${ }^{1}$ Universiti Teknologi MARA Selangor (UiTM) Aras 5 \& 7, Malaysia \\ ${ }^{2}$ Universiti Kebangsaan, Malaysia
}

Submission: June 6, 2018; Published: June 18, 2018

*Corresponding author: Azlan Ahmad Kamal, Universiti Teknologi MARA Selangor (UiTM) Aras 5 \& 7, Kampus Puncak Alam, Selangor Darul Ehsan, Malaysia, Email: azlankamal@gmail.com

\begin{abstract}
Participating in physical activity usually started with one or more reason. This reason then turns into goal to achieve. This is how people derive their motivation to doing physical activity. Ryan [1] investigate fifteen potential motivation of exercising including fun and enjoyment; improve cardiovascular fitness and ongoing good health. Woolf [2], the motivations to engage in physical activity were shown by cluster that evaluates six elements. The elements include competence challenge motivation, appearance motivation, and relaxation motivation, satisfaction with fitness, involvement with fitness and involvement with health. These elements than categorize into few cluster that shows the respondent level of motivation. The descriptive analysis was used to determine the frequency and the mean of the data. The study use Exercise Motivation Inventory (EMI-2) and International, Physical Activity Questionnaire (IPAQ) and also Theory of reasoned of action as a based. This research found that, all five motive affect the involvement of the individual in physical activity with the significant of $p$-value $=.000$. Besides, the motive that give affect the most towards the individual is social, challenge and fitness. Meanwhile, the motives that preferred by males are fitness and challenge, while for female teacher is appearance and health.
\end{abstract}

Keywords: Motives; Physical activity; Teachers; Health

\section{Introduction}

According to Gordon, Roopchand-Martin \& Hunter (2013), they found that both man and women have a motivation to perform physical activity because of they wanted to manage their weight and also their physical appearance. This shows that there are different motive to perform physical activity by men and women. Recently, in Aljazeera news writing by Stephanie Scawen on 3 Feb 2016 headline is Obesity Statistic Ring Alarm Bells in Malaysia state that $14 \%$ of Malaysians were considered obese, to compare with previous time the number of obese people increase rapidly. Type of food and all the facilities provided leading to this situation. For example, people prefer to ride the car even they can use the pedestrian to walk from one to another place. This shows that the level of the motivation to perform any activity that is related to the physical is very low among Malaysian.

According to Scawen (2016) in a developing city, they emphasize more on the road and highway rather than pedestrian or walk path. People here prefer to drive that use their own feet. Hence, this writing wanted to observe the level of the motive to perform physical activity among Malaysian especially teacher. Participating in physical activity usually started with one or more reason. This reason then turns into goal to achieve. This is how people derive their motivation to doing physical activity. Jaffee
(1999) investigate fifteen potential motivation of exercising including fun and enjoyment; improve cardiovascular fitness and ongoing good health.

\section{Method}

This study is using probability sampling by using simple random technique. This sampling procedure is use to make sure that all subject have the same probability to be selected as a respondent. This is most appropriate technique because the sample will represent entire teacher population in Malaysia. Since the number or teacher in Malaysia almost half amount from the total of government servant, thus teacher in Sekolah Menengah Seksyen 9, Shah Alam had been selected. This is because, the school located at the urban area which can also represent people at the same area and there are near to get assessing too many facilities. So the probability to perform physical activity is high. The instrument is developing to measure the dependent variables. The instrument is developing to observe each of the elements in motive that might affect the level of the physical activity for the respondent. The evidence from the survey later is used as the central data. The study will be separated into three sections which are demographic data of the respondent, physical activity and motive in physical activity. The questionnaire will be from Markland \& Hardy (1992) for 
the Exercise Motivational Inventory (EMI-2) and from Ajzen \& Fishbein (1967) for the theory that will be the base for the study and lastly is the item from IPAQ.

Researchers are also using the Ainsworth et al. Compendium (Med Sci. Sports Med 2000) to obtain average MET scores for each type of activity. For example; all of the included and the average MET value for walking were invented. The same procedure was carried out to moderate intensity activity and intensity of extreme activities. These values continue to be used for data analysis for IPAQ: Running = 3.3 Mets, Mets Simple PA 4.0 and PA 8.0 Energy Mets. Using these values, the four ongoing marks are defined: Walking (minutes / week) $=3.3$ minutes* walk* go days, Medium (minutes / week) $=4.0^{*}$ simple* medium intensity activity minutes a day, High- energy (minutes / week) $=8.0 *$ strong intensity outdoor activities minutes* intensity day. Total physical activity (minutes $/$ week) $=$ total + Medium
+ powered MET minutes Walking / week scores. MET and Value Calculation Formula of MET-minutes / week.

Descriptive analysis using SPSS version 19.0 was used to analyze the mean, frequency and percentage of the demographic characteristics of the staff of local university. To determine an overall score of physical activity, every answer will be analyzed by counting Metabolic Equivalent Task (MET) -min per week. All responses were summed to get the statistics. Likert Scale analysis was used to determine the level of physical activity in all the 42 items, with the lowest score is one (1) and the highest score is five (5).

\section{Result and Discussion}

The study involved a total of 62 teachers with diverse demographic backgrounds such as gender, race, age, marital status, expertise and BMI (Table 1).

Table 1: Demographic Profiles of teachers.

\begin{tabular}{|c|c|c|}
\hline Demographic & Frequency & Percent \\
\hline \multicolumn{3}{|c|}{ Sex } \\
\hline Male & 13 & $21.0 \%$ \\
\hline Female & 49 & $79.0 \%$ \\
\hline \multicolumn{3}{|c|}{ Race } \\
\hline Malay & 55 & $88.7 \%$ \\
\hline Chinese & 4 & $6.5 \%$ \\
\hline India & 2 & $3.2 \%$ \\
\hline Others & 1 & $1.6 \%$ \\
\hline \multicolumn{3}{|c|}{ Age } \\
\hline Between 21-30 years & 14 & $22.6 \%$ \\
\hline Between $31-40$ years & 23 & $37.1 \%$ \\
\hline Between $41-50$ years & 16 & $25.8 \%$ \\
\hline More than 50 years & 9 & $14.5 \%$ \\
\hline \multicolumn{3}{|c|}{ Status } \\
\hline Married & 51 & $82.3 \%$ \\
\hline Single & 11 & $17.7 \%$ \\
\hline \multicolumn{3}{|c|}{ Expertise } \\
\hline Language & 22 & $35.5 \%$ \\
\hline Science & 14 & $22.6 \%$ \\
\hline Humanitarian & 15 & $24.2 \%$ \\
\hline Technical & 11 & $17.7 \%$ \\
\hline \multicolumn{3}{|c|}{ BMI } \\
\hline Underweight & 2 & $3.2 \%$ \\
\hline Normal & 33 & $53.2 \%$ \\
\hline Overweight & 17 & $27.4 \%$ \\
\hline Obesity & 10 & $16.1 \%$ \\
\hline
\end{tabular}




\section{Analysis 1}

Kruskal Wallis analysis was used to identify the differences of motives for staff involvement in physical activity according to their BMI (Table 2).

Table 2: Differences of Motives and Physical Activity according to Gender.

\begin{tabular}{|c|c|c|c|c|c|c|}
\hline & IPAQ avg & Appearance Avg & Social Avg & Challanges Avg & Fitness Avg & health \\
\hline $\begin{array}{c}\text { Mann- } \\
\text { Whitney }\end{array}$ & 182 & 253 & 301.5 & 202 & 175.5 & 281.5 \\
\hline Wilcoxon W & 1407 & 344 & 1526.5 & 1427 & 1400.5 & 372.5 \\
\hline Z & -3.155 & -1.175 & -0.295 & -2.023 & -2.479 & -0.643 \\
\hline $\begin{array}{c}\text { Asymp. Sig. } \\
\text { (2-tailed) }\end{array}$ & 0.002 & 0.24 & 0.768 & 0.043 & 0.013 & 0.52 \\
\hline
\end{tabular}

\section{Analysis 2}

Kruskal-Wallis $\mathrm{H}$ analysis was conducted to determine if there is a relationship between the several motives for involvement with physical activity among teachers (Table 3).

Table 3: Relationship between Motives and Physical Activity.

\begin{tabular}{|c|c|c|c|c|c|}
\hline & Avg_Appearance & Avg_Social & Avg_Challanges & Avg_Fitness & Avg_Health \\
\hline Chi-Square & 0.733 & 3.573 & 7.854 & 10.143 & 2.372 \\
\hline df & 2 & 2 & 2 & 0.006 & 2 \\
\hline Asymp. Sig. & 0.693 & 0.168 & 0.02 & 0.185 \\
\hline
\end{tabular}

A Kruskal-Wallis $\mathrm{H}$ test showed that there was a statically difference in physical activity level between the different motive which is challenge and fitness motive $\mathrm{X} 2(2)=7.854,10.143$, $\mathrm{P}=0.020, .006$. An inspection of the mean ranks for the group suggest that the high physical activity respondent had the higher motive (appearance, social, challenge, fitness and health), with the low physical activity respondent score the lowest. Thus, type of motive that effect the physical activity among respondent is health and fitness motive with $\mathrm{p}$ value .020 and .006 . The motive that had been pick the most is challenge and fitness. The findings showed that teachers do more moderate physical activity in daily life. As for motives for involvement, there is a difference in motives for teachers' involvement in physical activity by gender, age, but in this study however there is no difference in motives for teachers' involvement in physical activity and weight status based on BMI. In other words, even if they are considered as overweight, physical activity involvement is not the determinant to reduce weight.

Similarly, there are no significant relationships between several motives and physical activity involvement as well. These include appearance, health and fitness, and challenge although there was a weak relationship with social factor for physical activity. This means, keeping their body in shape and for fitness purpose are not as important as being with friends while engaging in physical activity among the staff. Participating in physical activity may establish new friends that share a common interest and help to develop a support network.

\section{Conclusion and Suggestion}

From the IPAQ test, the level of physical of physical activity among the secondary school teacher had been shown. Based on the finding from the study that had been made, it was indicates that the level of the physical activity among secondary school teacher is moderate. In addition, male's teacher recorded the higher level of physical activity compare to female teacher. The motives that effect physical involvement among teacher are social, challenge and fitness. Meanwhile, male's teacher more motivated to perform physical activity because of the fitness and challenge motive, while female teacher motivated to perform physical activity because of the appearance and health motives. Last but not least, the finding shows male teacher are more motivated to get engage with physical activity compared to female teacher. It can be conclude that all of the research questions are being answered and the entire research objective had been achieved.

\section{References}

1. Ryan RM, Deci EL (2000) Intrinsic and Extrinsic motivations: classic definition and new direction. 25(1): 54-67.

2. Woolf B, Burleson W, Arroyo I, Dragon T, Cooper D, et al. (2009) AffectAware Tutors: Recognising and Responding to Student Affect. Int J Learn Technol 4 (3/4): 129-164.

3. Alayode AM, Babalola AJ, Oyesegun OO (2014) Perceived Motives For Participation In Leisure-Time Physical Activity Among Employees Of Tertiary Institutions In Ondo State, Nigeria, p.1-14.

4. Hashim HA (2016) Memahami aspek halangan untuk bersenam. Utusan

5. Blasio AD Automatic report of the International Physical Activity Questionnaire. Microsoft Excel.

6. Bon IV (2015) Please remind me to get active, the influence of motivation \& triggers on physical activity, pp. 1-65.

7. Cagas J, Torre B, Manalastas EJ (2014) Pampapayat, para lumakas, to be healthy. Motives exploring Filipino for exercise. Journal of Psychology 47(1):145-161. 
8. Carron DG, Sharmella RM (2013) Motives For Exercise Participation in Urban Communities in Jamaica. Caribbean Journal of Psychology 5(1): 1-13.

9. Chatzisarantis NKD, Kamarova S, Wang J (2015) Developing And Evaluating Utility Of School-Based Intervention Programs In Promoting Leisure-Time Physical Activity: An Application of The Theory of Planned Behavior. National Institute of Education.

10. Chaubal SR (2011) Effect of knowledge of exercise benefits on attitude, motivation, and exercise participation pp. 1-64.

11. Crofts C, Schofield G, Dickson G (2012) Women-only mass participation sporting events: does participation facilitate changes in physical activity?. Annals of Leisure Research 15(2): 148-159.

12. Dunton GF, Cousineau M, Reynolds KD (2010) The intersection of public policy and health behavior theory in the physical activity arena Journal of physical activity and health 1: S91- S98.

13. Ennis G (2012) Relationship between exercise motivation, self-esteem, eating, attitudes and body image satisfaction among undergraduate students.

14. Fitz Gerald LZ (2015) Categorization and determinants of physical activity among nursing students. Journal of Nursing Education and Practice 5(5)

15. Garriguet D, Tremblay S, Colley C (2015) Comparison of physical activity adult questionnaire result with accelerometer data 26(7): 11-

16. Kinnafick FE (2013) Social contextual and environmental determinants of physical activity adoption, adherence and well-being.

17. Molanorouzi K, Khoo S, Morris T (2015) Motives for Adult Participation in Physical Activity: Type of Activity, Age, and Gender. Public Health 15: 66.

18. Natanya M, Ayesha LBD (2014) Gender Differences in South African Generation Y Students' Motives for Engaging in Physical Activity. Journal of Social Science 5(21).
19. Piskozub Anna T (2013) Exercise Motivators and Exercise Causality Among Andrews University Students: a Correlational Study.

20. Ries F, Hein V, Pihu M, Armenta JMS (2012) Self-identity as a component of the theory of planned behaviour in predicting physical activity. European Physical Education Review.

21. Roberts S, Reeves M, \& Ryrie A (2014) The influence of physical activity, sport and exercise motives among UK-based university. Journal of Further and Higher Education 39(4): 598-607.

22. Rossmann C (2013) Identifying effective message for the promotion of physical activity. The international journal of communication and health p.1-11.

23. Shirvani ZG, Ghofranipour F, Gharakhanlou R, Kazemnejad A (2015) Determinants of Physical Activity Based on the Theory Planned Behavior in Iranian Military Staff's Wives: A Path Analysis. Journal of Health and Science 7(3): 230-239.

24. Strom M, Uckelstam CJ, Andersson G, Hassmen P, Umefjord G, et al (2013) Internet-delivered therapist-guided physical activity for mild to moderate depression: a randomized controlled trial 1: e178.

25. Sun G, Acheampong RA, Lin H, Pun VC (2015) Understanding Walking Behavior among University Students Using Theory of Planned Behavior. Journal of Environmental Research and Public Health 12(11): 1379413806.

26. Tennur YL (2015) Phyiscal activity levels and psychological well-being: A case study of University Students. Social and Behavioral Sciences 186: 739-743.

27. Thompson A (2014) The impact the amount of high school physical education has on the physical activity habits of traditional college freshmen. Faculty scholarship exercise and sport science.

Your next submission with Juniper Publishers

$$
\text { will reach you the below assets }
$$

- Quality Editorial service

- Swift Peer Review

- Reprints availability

- E-prints Service

- Manuscript Podcast for convenient understanding

- Global attainment for your research

- Manuscript accessibility in different formats ( Pdf, E-pub, Full Text, Audio)

- Unceasing customer service

Track the below URL for one-step submission https://juniperpublishers.com/online-submission.php 